\title{
Novel inflammatory biomarkers may reflect subclinical inflammation in young healthy adults with obesity
}

\author{
Tadeusz Osadnik', 2, Kamil Bujak', Kamila Osadnik2, Hanna Czarnecka ${ }^{4}$, Natalia Pawlas ${ }^{2,5}$, Rafał Reguła ${ }^{3}$, \\ Martyna Fronczek ${ }^{6,7}$, Mateusz Lejawa $^{2,7}$, Marcin Gawlita ${ }^{8}$, Małgorzata Gonera $^{9}$, Marta Góral ${ }^{10}$, \\ Joanna K. Strzelczyk ${ }^{6}$, Marek Gierlotka ${ }^{3,11}$, Andrzej Lekston ${ }^{3}$, Janusz Kasperczyk ${ }^{12}$, Lech Poloński ${ }^{3}$, \\ Mariusz Gąsior ${ }^{3}$
}

${ }^{1} 2^{\text {nd }}$ Department of Cardiology and Angiology, Silesian Center for Heart Diseases, Zabrze, Poland

${ }^{2}$ Chair and Department of Pharmacology, School of Medicine with the Division of Dentistry in Zabrze, Medical University of Silesia, Katowice, Poland

${ }^{3} 3^{\text {rd }}$ Department of Cardiology, School of Medicine with the Division of Dentistry in Zabrze, Medical University of Silesia

in Katowice, Silesian Center for Heart Diseases, Zabrze, Poland

${ }^{4}$ Clinical Laboratory, Silesian Center for Heart Diseases, Zabrze, Poland

${ }^{5}$ Institute of Occupational Medicine and Environmental Health, Sosnowiec, Poland

${ }^{6}$ Department of Medical and Molecular Biology, School of Medicine with the Division of Dentistry in Zabrze, Medical University of Silesia, Katowice, Poland

${ }^{7}$ Genomics Laboratory, Kardio-Med Silesia Science and Technology Park, Zabrze, Poland

${ }^{8}$ Department of Environmental Medicine and Epidemiology, School of Medicine with the Division of Dentistry in Zabrze, Medical University of Silesia, Katowice, Poland

${ }^{9}$ Regional Specialised Hospital No. 4, Anaesthesiology and Intensive Care Unit, Bytom, Poland

${ }^{10}$ Students' Scientific Society, $3^{\text {rd }}$ Department of Cardiology, School of Medicine with the Division of Dentistry in Zabrze,

Medical University of Silesia in Katowice, Silesian Center for Heart Diseases, Zabrze, Poland

${ }^{11}$ Department of Cardiology, University Hospital in Opole, Faculty of Natural Sciences and Technology, Institute of Medicine, University of Opole, Poland

${ }^{12}$ Centre of Polymer and Carbon Materials of the Polish Academy of Sciences Zabrze, Poland

\begin{abstract}
Introduction: Obesity is often accompanied by low-grade inflammation. In recent years a few blood-based inflammatory markers — neutrophil-to-lymphocyte ratio (NLR), derived neutrophil-to-lymphocyte ratio (dNLR), platelet-to-lymphocyte ratio (PLR), lymphocyteto-monocyte ratio (LMR), and monocyte-to-high-density lipoprotein ratio (MHR) - have been identified. They have been proven to correlate well with established inflammatory markers such as hsCRP and have a prognostic value among others in patients with coronary artery disease, heart failure, and malignancies. The aim of the study was to find markers associated with obesity in young heathy adults. Material and methods: The study group included 321 young healthy adults aged 18-35 years (210 males and 111 females). Partial least squares regression analysis was used to find variables associated with body mass index (BMI). Analysed variables included complete blood count, lipid profile, sex hormone levels, acute-phase protein levels, and blood-based inflammatory markers.

Results: Variables with the strongest association with BMI in the group of men were HDL\% and apolipoprotein B, and in the group of women, HDL, HDL \% , triglycerides, and MHR. Novel inflammatory markers were not associated with BMI, except MHR. We found significant $(p<0.001)$ correlations between novel biomarkers (NLR, dNLR) and hsCRP and fibrinogen levels in the group of subjects with obesity. Conclusions: Blood-based inflammatory markers significantly correlate with hsCRP and fibrinogen in young healthy adults with obesity, which may reflect the subclinical inflammation in this group of individuals. (Endokrynol Pol 2019; 70 (2): 135-142)
\end{abstract}

Key words: obesity; inflammation; complete blood count

\section{Introduction}

Overweight and obesity are becoming more frequent in the population of young adults. Although mortality rates in this cohort are low, the presence of overweight and obesity during this period may significantly increase the risk of chronic diseases later in life $[1,2]$ and have socio-economic consequences [3]. The development of obesity is affected by many factors including behavioural, environmental, and genetic factors $[2,4$, 5]. In a small percentage of cases, obesity is caused by endocrine disorders. On the other hand, in individuals with excessive body weight, cytokines, inflammatory factors, and adipokines, secreted by adipose tissue 
and developing insulin resistance, are responsible for systemic and hormonal axis dysregulation, i.e. the sex hormone system, thyroid gland function, and vitamin D homeostasis [6]. However, not all patients who are overweight or obese experience such complications. For these reasons, one of the important primary prevention tools for obesity-related illnesses would be the ability to identify patients at high risk of developing obesity-related diseases as opposed to people referred to as "metabolically healthy obese" $[7,8]$.

The subclinical inflammation accompanying overweight and obesity may be a factor that identifies patients at risk of developing obesity complications because inflammation plays a major role in the development of insulin resistance and cardiometabolic complications [9]. In addition to commonly known C-reactive protein (CRP) and fibrinogen, interleukin-6 (IL-6) and tumour necrosis factor alpha (TNF- $\alpha$ ) have also been found to be associated with obesity [9]. However, these markers are not readily obtainable in everyday clinical practice. Therefore, it is necessary to search for cheaper and more accessible biomarkers of inflammation related to body mass index (BMI). Several recent studies have drawn attention to easily available blood-based inflammatory markers [10, 11]. Relationships between neutrophil to lymphocyte ratio (NLR) [10-15], derived neutrophil to lymphocyte ratio (dNLR) [10], platelet to lymphocyte ratio (PLR) [16], lymphocyte to monocyte ratio (LMR) [12, 14, 17], monocyte to high-density lipoprotein ratio (MHR) [18, 19], inflammation, and prognosis in cardiovascular diseases and cancer have all been reported. The association of these inflammatory parameters with BMI remains unclear. The aim of our study was to find biomarkers associated with obesity in the group of young heathy adults.

\section{Material and methods}

\section{Study group}

The study group consisted of individuals aged 18-35 years from the MAGNETIC (Metabolic And GeNETic Profiling of Young Adults with and without a Family History of Premature Coronary Heart Disease) project, who were healthy descendants of patients hospitalised in the Silesian Centre for Heart Diseases because of premature coronary artery disease (myocardial infarction or angiographically confirmed stable coronary artery disease that occurred before age 55 years in men and before 65 years in women) [20, 21]. The study flow chart is shown in Figure 1. The exclusion criteria included use of medicines (including contraceptives in women), chronic conditions, acute infections, pregnancy, and lactation. All women were recruited during menstrual bleeding. Blood pressure was measured in each patient at the time of enrolment. Detailed information on family history of neoplasm, cardiovascular, gastrointestinal, haematological, metabolic, nephrological, rheumatic, and allergic diseases was also collected.

The subjects were divided into three groups according to value of body mass index (BMI) (body mass $[\mathrm{kg}] /$ body height $[\mathrm{m}]^{2}$ ): normal body mass group (BMI 18.5-25.0 kg/m²); overweight (BMI between $\left.\geq 25.0,<30.0 \mathrm{~kg} / \mathrm{m}^{2}\right)$; and obesity group (BMI $\left.\geq 30.0 \mathrm{~kg} / \mathrm{m}^{2}\right)$. Underweight individuals (BMI $<18.5 \mathrm{~kg} / \mathrm{m}^{2}$ ) were excluded from this analysis.

\section{Blood samples}

In each patient, blood was collected between 7 a.m. and 9 a.m., approximately $8-10 \mathrm{~h}$ after the last meal. Complete blood count (CBC) was performed on a Sysmex XE2100 (Sysmex Corporation, Kobe, Japan), and biochemical parameters were assessed with a Cobas 6000 (Roche Diagnostics, Indianapolis, IN, USA) using Roche reagents. We determined $\mathrm{CBC}$, the level of fibrinogen, ceruloplasmin, aspartate aminotransferase (AST), alanine aminotransferase (ALT), gamma-glutamyltransferase (GGT), bilirubin, alkaline phosphatase (ALP), total protein, lipid profile, apolipoprotein A1, apolipoprotein $B$, homocysteine, cystatin $C$, vitamin $D$, glucose, lactate dehydrogenase $(\mathrm{LDH})$, haemoglobin $\mathrm{A}_{1 \mathrm{c}}\left(\mathrm{HbA}_{1 \mathrm{c}}\right)$, creatinine, uric acid, sodium, potassium, calcium, phosphorus, and high-sensitivity C-reactive protein (hsCRP). In addition, we determined the following hormones: thyroid-stimulating hormone (TSH), follicle-stimulating hormone (FSH), luteinising hormone ( $\mathrm{LH})$, oestradiol, progesterone, total testosterone, free testosterone, and sex hormone binding protein (SHBG).

\section{CBC-based inflammatory markers}

Based on $\mathrm{CBC}$ parameters and HDL (high-density lipoprotein) level, we also calculated factors that were reported to correlate well with markers of inflammation: NLR, PLR, LMR, dNLR (calculated by dividing the neutrophil count by the difference between leukocytes and neutrophil counts), and MHR [14].

\section{Statistical analysis}

Values of continuous and dichotomous variables concerning clinical characteristics between groups of individuals with normal body weight, overweight, and obesity were compared with appropriate tests for trends - Jonckheere-Terpstra and Cochrane-Armitage tests. To evaluate the relationship between biomarkers and BMI, considering the large number of analysed variables and the co-linearity of some of the variables analysed, we used partial least squares regression (PLSR). First, because the normality assumption for analysed biomarker concentrations was not fulfilled in either the group of women or men, concentrations were log-transformed. Reassessment of normality of distribution did not show significant deviations from normal distribution. Second, the variables were mean-centred and divided by standard deviation. PLSR analysis, which we applied in this study, relies on a transformation of 57 analysed independent variables (log-transformed biomarker concentrations) into latent factors that describe maximum correlation between analysed variables and the dependent variable (BMI). Each of these latent factors is a pattern of biomarkers that has an association with BMI. The influence of biomarkers on a latent factor, and consequently their relationship with $\mathrm{BMI}$, is reflected by factor loadings. The higher the loading, the stronger this relationship [22]. In addition, we performed a univariate regression analysis of the association of analysed variables with BMI. Additionally, we analysed correlations between novel blood-based inflammatory biomarkers and well-established inflammatory biomarkers (hsCRP, fibrinogen) across BMI categories (normal body weight, overweight, and obesity). Due to the large number of these analyses, a correction was made for multiple comparisons. Statistically significant results where those for which the false discovery rate (FDR) was less than 0.05 .

The study conformed to the Declaration of Helsinki and was approved by the Ethics Committee of the Institute of Occupational Medicine and Environmental Health, Sosnowiec, Poland. Informed, written consent was obtained from all subjects enrolled in the study. 


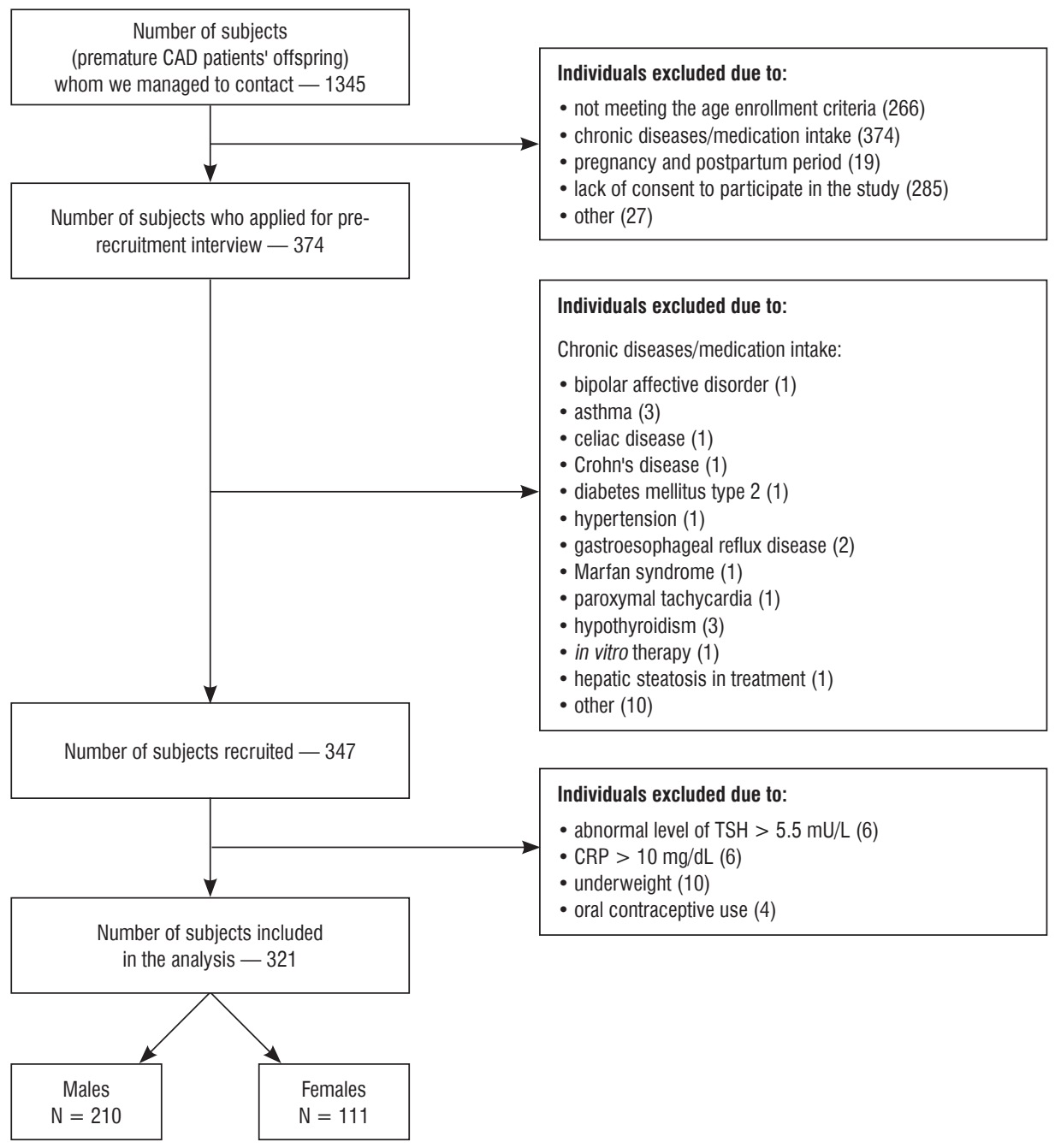

Figure 1. Flow chart of study population. $C A D-$ coronary artery disease; $C R P-C$-reactive protein

\section{Results}

\section{Characteristics of the study group}

Baseline characteristics of the study group are shown in Table I. Subjects with obesity, compared to those with overweight and normal weight, were older and more frequently male. There was also a significant trend among groups associated with lower physical activity and higher alcohol consumption, as well as with higher blood pressure in groups with overweight and obesity. The percentage of subjects with higher education was lower in the group with obesity. There was no significant relationship between subjects with normal body weight, overweight, and obesity in terms of sleep duration and smoking.

\section{Relationship between analysed parameters and $\mathrm{BMI}$}

The results of the PLSR analysis indicate that the most significant contributors to differentiation of people with normal body weight and with obesity in the group of men were $\mathrm{HDL} \%$ and apolipoprotein $\mathrm{B}$, and in the group of women, HDL, HDL \%, MHR, and triglycerides (Tab. II). In both the female and male groups, separation of individuals with normal body weight and with obesity proceeded along first latent factor or along the horizontal axis in Figures $2 \mathrm{~A}$ and $2 \mathrm{~B}$. The differentiation of individuals in terms of BMI values in both men and women were not influenced by blood-based inflammatory biomarkers, except MHR. Additionally, univariate analysis of correlation between analysed variables and BMI, similar to the PLSR analysis results, showed that inflammatory, hormonal, and lipid parameters had the strongest association with BMI. Correlations with BMI related to blood-based inflammatory markers, except for MHR, were weak and, after adjustment for multiple intergroup comparisons, were insignificant (NLR, dNLR, LMR) or borderline significant (PLR in group of men) (Tab. III and IV).

\section{$C B C$ parameters in terms of $B M I$}

The number of leukocytes, monocytes, lymphocytes, and neutrophils were higher in the overweight and 
Table I. Baseline characteristics of the study population

\begin{tabular}{lcccc}
\hline Variables & $\begin{array}{c}\text { Individuals with normal } \\
\text { body weight }(\mathbf{n}=\mathbf{1 5 8})\end{array}$ & $\begin{array}{c}\text { Overweight individuals } \\
(\mathbf{n}=\mathbf{1 1 2})\end{array}$ & $\begin{array}{c}\text { Individuals with obesity } \\
\text { (n = 51) }\end{array}$ & $\begin{array}{c}\mathbf{p} \text {-value } \\
\text { for trend }\end{array}$ \\
\hline Age (years) & $28.0(24.0-32.4)$ & $29.7(26.2-33.0)$ & $31.4(27.8-33.4)$ & 0.003 \\
\hline Sex (male) & $84(53.2)$ & $90(80.4)$ & $36(70.6)$ & $<0.0001$ \\
\hline Higher education & $91(57.6)$ & $62(55.4)$ & $19(37.3)$ & 0.04 \\
\hline Low physical activity level & $31(19.4)$ & $30(26.6)$ & $22(42.3)$ & 0.005 \\
\hline $\begin{array}{l}\text { Less than six hours of sleep per night } \\
\text { during weekdays }\end{array}$ & $58(36.7)$ & $45(40.2)$ & $20(39.2)$ & 0.83 \\
\hline $\begin{array}{l}\text { Less than six hours of sleep per night } \\
\text { during the weekends }\end{array}$ & $16(10.1)$ & $8(7.1)$ & $3(5.9)$ & 0.53 \\
\hline Good financial situation & $89(56.3)$ & $60(53.6)$ & $24(47.1)$ & 0.51 \\
\hline $\begin{array}{l}\text { SBP at the time of recruitment } \\
\text { [mm Hg] }\end{array}$ & $121(116-129)$ & $129(120-138)$ & $132(125-140)$ & $<0.0001$ \\
\hline $\begin{array}{l}\text { DBP at the time of recruitment } \\
\text { [mm Hg] }\end{array}$ & $76(70-83)$ & $80(71-85)$ & $82(75-90)$ & 0.004 \\
\hline Current smoker & $37(23.4)$ & $43(38.4)$ & $14(27.5)$ & 0.03 \\
\hline Alcohol [units per week] & $2(1-6)$ & $4(2-8)$ & $4(1-9)$ & 0.02 \\
\hline
\end{tabular}

Continuous variables are presented as the median (interquartile range). Categorical variables are presented as the number of patients (percentages)

Table II. Factor loadings for latent factor 1 in male and female groups

\begin{tabular}{|c|c|c|c|}
\hline \multicolumn{2}{|c|}{ Male group } & \multicolumn{2}{|c|}{ Female group } \\
\hline Variable & $\begin{array}{c}\text { Latent } \\
\text { factor } 1\end{array}$ & Variable & $\begin{array}{c}\text { Latent } \\
\text { factor } 1\end{array}$ \\
\hline Apolipoprotein B & 0.27 & MHR & 0.27 \\
\hline Triglycerides & 0.26 & Triglycerides & 0.27 \\
\hline LDL & 0.25 & Fibrinogen & 0.24 \\
\hline Total cholesterol & 0.24 & Free testosterone & 0.23 \\
\hline GGT & 0.23 & hsCRP & 0.23 \\
\hline MHR & 0.23 & Uric acid & 0.22 \\
\hline ALT & 0.22 & ALP & 0.21 \\
\hline Uric Acid & 0.2 & ALT & 0.21 \\
\hline WBC & 0.18 & Apolipoprotein B & 0.20 \\
\hline Fibrinogen & 0.18 & GGT & 0.19 \\
\hline HDL & -0.20 & Apolipoprotein A1 & -0.16 \\
\hline Testosterone & -0.22 & SHBG & -0.21 \\
\hline SHBG & -0.23 & $\mathrm{HDL}$ & -0.28 \\
\hline HDL (\%) & -0.29 & HDL (\%) & -0.29 \\
\hline \multicolumn{4}{|c|}{$\begin{array}{l}\text { Factor loadings for latent factor } 1 \text { in male and female groups are shown in } \\
\text { the above table. The higher the absolute value of the factor loading of a given } \\
\text { variable for a given latent factor, the greater the influence of this variable on the } \\
\text { determination of the score for a latent factor for a particular observation. } \\
\text { LDL - low-density lipoprotein; GGT - gamma-glutamyltransferase; } \\
\text { MHR - monocyte to high-density lipoprotein ratio; ALT — alanine } \\
\text { aminotransferase; WBC - white blood cells; HDL - high-density lipoprotein; } \\
\text { SHBG - sex hormone binding globulin; ALP - alkaline phosphatase; } \\
\text { hSCRP - high-sensitivity C-reactive protein }\end{array}$} \\
\hline
\end{tabular}

obesity groups compared with the group with normal body weight, while there was no association between platelet levels and BMI categories (Fig. 3).

\section{Correlation between hsCRP and blood-based inflammatory markers}

The correlation between hsCRP and levels of blood-based inflammatory markers was insignificant or weak in the groups with normal body weight and overweight; however, the correlation of blood-based inflammatory markers (NLR, dNLR) and hsCRP and fibrinogen was highly significant in the group of individuals with obesity (Tab. V).

\section{Discussion}

The results of recent studies have highlighted the special role of low-level chronic inflammation, which accompanies obesity in the development of insulin resistance and consequently contributes to the development of metabolic syndrome [23-26]. Excessive food consumption leads to numerous changes in intracellular metabolism, mainly in adipose tissue but also in tissues of other organs such as liver, pancreas, and muscles [27]. This results in inflammatory responses and release of proinflammatory cytokines (TNF- $\alpha$, IL-6, interleukin-1 $\beta$, and others) [28, 29]. In addition, inflammatory cells, mainly macrophages, which also play an important role in the inflammatory response, infiltrate the adipose tissue. Secretion of mediators of the inflammatory response leads to increased production of acute-phase proteins $[27,28]$.

Numerous studies have shown that inflammation is associated with an increased number of neutrophils, while lymphocytopaenia is a common response to physiological stress $[14,15,30]$. In pathologic conditions 

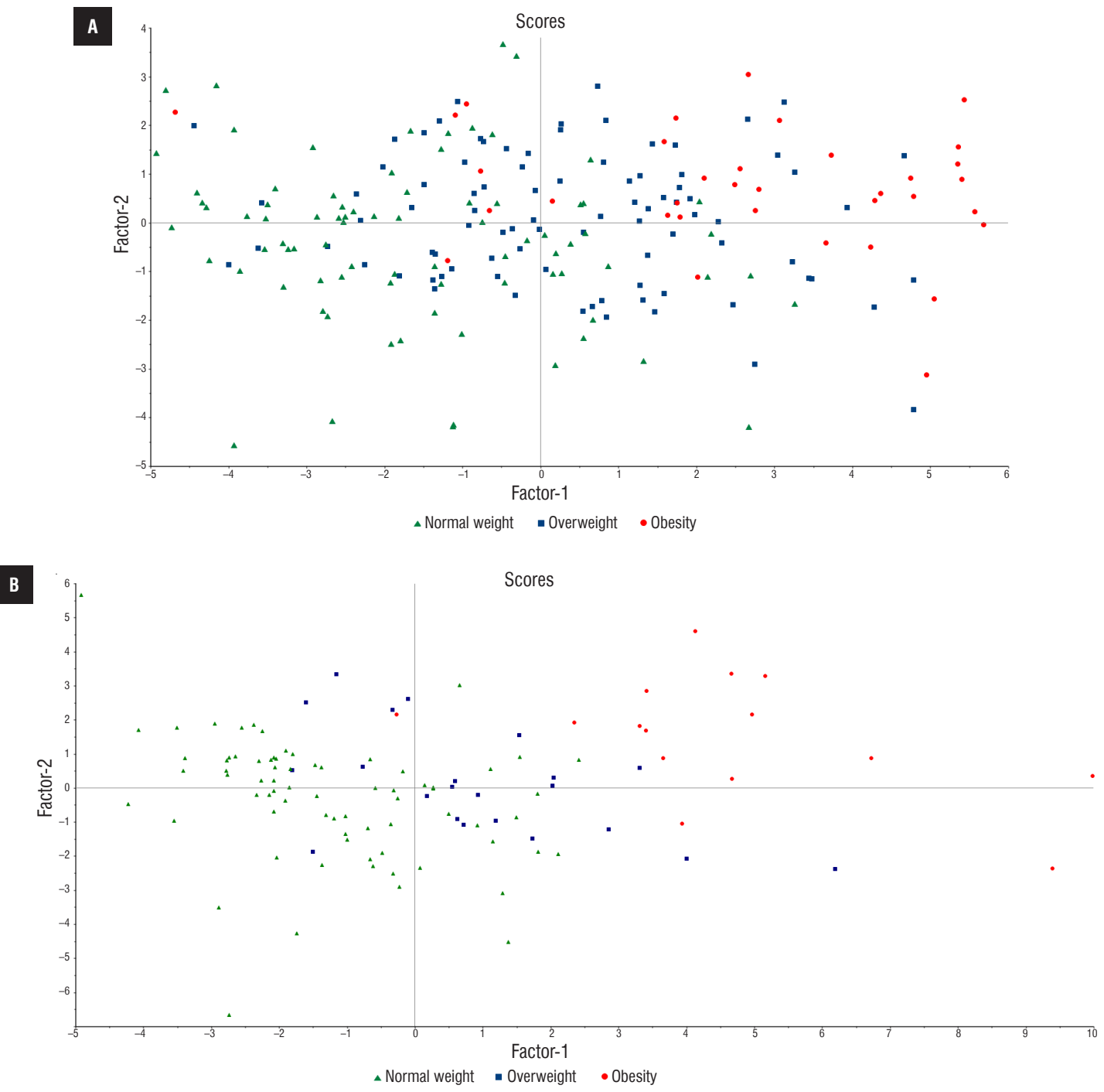

Figure 2AB. A. PLSR scores in the male group. The first two PLSR score-vectors describing the male group. The first component explains $12 \%$ of $X$ variance and $45 \%$ of calibrated $Y$ variance. Patients with lowest to highest BMI can be seen along the first factor. For visualisation purposes, patients were grouped into three BMI categories: normal weight (green triangles), overweight (blue squares), and obesity (red dots). B. PLSR scores in the female group. The first two PLSR score-vectors describing the female group. The first component explains $12 \%$ of $X$ variance and $52 \%$ of calibrated $Y$ variance. Patients with lowest to highest BMI can be seen along the first factor. For visualisation purposes, patients were grouped into three BMI categories: normal weight (green triangles), overweight (blue squares), and obesity (red dots)

where inflammation plays a major role, leukocytosis, neutrophilia, and lymphocytopaenia are associated with worse prognosis [14, 15, 30]. Lymphocytes, however, may play an important role in subclinical inflammation associated with increased BMI; we have shown that lymphocyte count increases across BMI categories. As demonstrated in animal models, lymphocytes are the first cells of the immune system that respond to abnormal adipocyte function associated with hypertrophy and hypoxia in obesity [31]. Lymphocytes then produce inflammatory cytokines, which are responsible for monocyte recruitment and infiltration of adipose tissue [32]. Perhaps, therefore, the inflammatory process associated with initial in- crease in BMI from normal weight to overweight is somewhat different in terms of pathophysiology from the inflammatory processes associated with chronic diseases, where the increase in neutrophil population and the decrease in the lymphocyte population is most often observed. This could explain the lack of correlation between hsCRP, fibrinogen, and blood-based inflammatory markers in normal weight and overweight subjects, and highly significant correlation in obese subjects where an increment in neutrophils is also observed. Novel blood-based inflammatory markers might expand the armamentarium of inflammatory markers that are useful in quantification of subclinical inflammatory response in obese patients. 
Table III. Univariate correlations with false discovery rate (FDR) value $<0.05$ between analysed variables and body mass index (BMI) in the male group. Correlations are sorted according to FDR values from most to least significant

\begin{tabular}{|c|c|c|c|c|}
\hline Variable & $\begin{array}{l}\text { Correlation } \\
\text { Coefficient }\end{array}$ & t-stat & p-value & FDR \\
\hline HDL (\%) & -0.5 & -8.28 & $1.52 \mathrm{e}-14$ & $4.40 \mathrm{e}-13$ \\
\hline Triglycerides & 0.49 & 8.13 & $3.89 \mathrm{e}-14$ & $7.51 \mathrm{e}-13$ \\
\hline GGT & 0.42 & 6.72 & $1.76 \mathrm{e}-10$ & $2.55 \mathrm{e}-09$ \\
\hline $\begin{array}{l}\text { Apolipoprotein } \\
\text { B }\end{array}$ & 0.42 & 6.58 & $3.70 \mathrm{e}-10$ & $4.29 \mathrm{e}-09$ \\
\hline SHBG & -0.41 & -6.53 & $4.94 \mathrm{e}-10$ & $4.78 \mathrm{e}-09$ \\
\hline Testosterone & -0.41 & -6.46 & $7.18 \mathrm{e}-10$ & $5.95 \mathrm{e}-09$ \\
\hline ALT & 0.41 & 6.42 & $8.97 \mathrm{e}-10$ & $6.50 \mathrm{e}-09$ \\
\hline MHR & 0.39 & 6.06 & $6.24 \mathrm{e}-09$ & $4.02 \mathrm{e}-08$ \\
\hline $\begin{array}{l}\text { Total } \\
\text { Cholesterol }\end{array}$ & 0.38 & 5.86 & $1.83 \mathrm{e}-08$ & $1.06 \mathrm{e}-07$ \\
\hline HDL & -0.37 & -5.76 & $3.05 \mathrm{e}-08$ & $1.61 \mathrm{e}-07$ \\
\hline LDL & 0.37 & 5.68 & $4.54 \mathrm{e}-08$ & $2.19 \mathrm{e}-07$ \\
\hline hsCRP & 0.35 & 5.32 & $2.70 \mathrm{e}-07$ & $1.21 \mathrm{e}-06$ \\
\hline Uric acid & 0.32 & 4.95 & $1.53 \mathrm{e}-06$ & $6.36 \mathrm{e}-06$ \\
\hline LDH & 0.31 & 4.64 & $6.15 \mathrm{e}-06$ & $2.38 \mathrm{e}-05$ \\
\hline Fibrinogen & 0.29 & 4.34 & $2.25 \mathrm{e}-05$ & $8.15 \mathrm{e}-05$ \\
\hline AST & 0.28 & 4.21 & $3.81 \mathrm{e}-05$ & 0.0001 \\
\hline Ceruloplasmin & 0.27 & 4.1 & $5.96 \mathrm{e}-05$ & 0.0002 \\
\hline WBC & 0.26 & 3.95 & 0.0001 & 0.0003 \\
\hline Glucose & 0.26 & 3.89 & 0.0001 & 0.0004 \\
\hline Neutrophils & 0.23 & 3.38 & 0.0009 & 0.002 \\
\hline Progesterone & -0.22 & -3.3 & 0.001 & 0.003 \\
\hline Phosphate & -0.21 & -3.09 & 0.002 & 0.006 \\
\hline RBC & 0.2 & 2.97 & 0.003 & 0.008 \\
\hline Monocytes & 0.19 & 2.72 & 0.007 & 0.02 \\
\hline $\mathrm{HbA1c}$ & 0.18 & 2.66 & 0.008 & 0.02 \\
\hline Haemoglobin & 0.18 & 2.59 & 0.01 & 0.02 \\
\hline Lymphocytes & 0.18 & 2.56 & 0.01 & 0.02 \\
\hline Albumin & -0.17 & -2.53 & 0.01 & 0.02 \\
\hline PLR & -0.16 & -2.31 & 0.02 & 0.04 \\
\hline
\end{tabular}

$\mathrm{FDR}$ — false discovery rate; $\mathrm{BMI}$ — body mass index; $\mathrm{HDL}$ — high-density lipoprotein; GGT — gamma-glutamyltransferase; SHBG — sex hormone binding globulin; ALT — alanine aminotransferase; MHR — monocyte to high-density lipoprotein ratio; LDL — low-density lipoprotein; hsCRP — highsensitivity C-reactive protein; $\mathrm{LDH}$ - lactate dehydrogenase; AST — aspartate aminotransferase; WBC — white blood cells; RBC — red blood cells;

PLR - platelet to lymphocyte ratio

\section{Strengths and limitations}

A potential limitation of the study is that all patients had a family history of premature coronary artery disease. The strength of our study is the complexity of performed biochemical analyses and the homogenous
Table IV. Univariate correlations with false discovery rate (FDR) value $<0.05$ between analysed variables and body mass index (BMI) in the female group. Correlations are sorted according to FDR values from most to least significant.

\begin{tabular}{|c|c|c|c|c|}
\hline Variable & $\begin{array}{l}\text { Correlation } \\
\text { Coefficient }\end{array}$ & t-stat & $p$-value & FDR \\
\hline Fibrinogen & 0.59 & 7.63 & $9.49 \mathrm{e}-12$ & $2.09 \mathrm{E}-10$ \\
\hline HDL & -0.59 & -7.6 & $1.12 \mathrm{e}-11$ & $2.09 \mathrm{E}-10$ \\
\hline hsCRP & 0.58 & 7.41 & $2.92 \mathrm{e}-11$ & $4.09 \mathrm{E}-10$ \\
\hline Triglycerides & 0.51 & 6.11 & $1.55 \mathrm{e}-08$ & $1.73 \mathrm{E}-07$ \\
\hline MHR & 0.5 & 6.07 & $1.91 \mathrm{e}-08$ & $1.79 \mathrm{E}-07$ \\
\hline HDL\% & -0.5 & -6.0 & $2.58 \mathrm{e}-08$ & $2.06 \mathrm{E}-07$ \\
\hline Uric acid & 0.47 & 5.63 & $1.43 \mathrm{e}-07$ & $1.00 \mathrm{E}-06$ \\
\hline SHBG & -0.44 & -5.06 & $1.69 \mathrm{e}-06$ & $1.05 \mathrm{E}-05$ \\
\hline $\begin{array}{l}\text { Free } \\
\text { testosterone }\end{array}$ & 0.43 & 5.01 & $2.11 \mathrm{e}-06$ & $1.18 \mathrm{E}-05$ \\
\hline ALT & 0.39 & 4.45 & $2.11 \mathrm{e}-05$ & 0.0001 \\
\hline $\begin{array}{l}\text { Apolipoprotein } \\
\text { A1 }\end{array}$ & -0.38 & -4.23 & $4.84 \mathrm{e}-05$ & 0.0002 \\
\hline ALP & 0.39 & 4.14 & $6.81 \mathrm{e}-05$ & 0.0003 \\
\hline Glucose & 0.36 & 4.02 & 0.0001 & 0.0004 \\
\hline Phosphate & -0.35 & -3.91 & 0.0002 & 0.0006 \\
\hline GGT & 0.3 & 3.23 & 0.002 & 0.006 \\
\hline Lymphocytes & 0.28 & 3.03 & 0.003 & 0.01 \\
\hline Cystatin C & 0.26 & 2.83 & 0.006 & 0.02 \\
\hline MCV & -0.24 & -2.58 & 0.01 & 0.03 \\
\hline $\mathrm{RBC}$ & 0.23 & 2.5 & 0.01 & 0.04 \\
\hline $\mathrm{HbA}_{1 \mathrm{C}}$ & 0.23 & 2.45 & 0.02 & 0.04 \\
\hline $\begin{array}{l}\text { Apolipoprotein } \\
\text { B }\end{array}$ & 0.23 & 2.43 & 0.02 & 0.04 \\
\hline \multicolumn{5}{|c|}{$\begin{array}{l}\text { FDR — false discovery rate; BMI — body mass index; HDL — high-density } \\
\text { lipoprotein; hsCRP — high-sensitivity C-reactive protein; MHR — monocyte to } \\
\text { high-density lipoprotein ratio; SHBG — sex hormone binding globulin; } \\
\text { ALT — alanine aminotransferase; ALP — alkaline phosphatase; GGT — gamma- } \\
\text { glutamyltransferase; LDH — lactate dehydrogenase; RBC — red blood cell; } \\
\text { MCV — mean corpuscular volume }\end{array}$} \\
\hline
\end{tabular}

group of healthy young adults. Use of the PLSR method has allowed simultaneous analysis of collinear variables such as HDL\%, HDL, apolipoprotein A1, or PLR, NLR, and LMR. Another advantage of our research is that all women were recruited during menstruation, which reduces the impact of hormonal changes associated with menstrual cycle.

\section{Conclusions}

Blood-based inflammatory markers, i.e. NLR and dNLR, significantly correlate with hsCRP and fibrinogen in young healthy adults with obesity, which may reflect the subclinical inflammation in this group of individuals. 

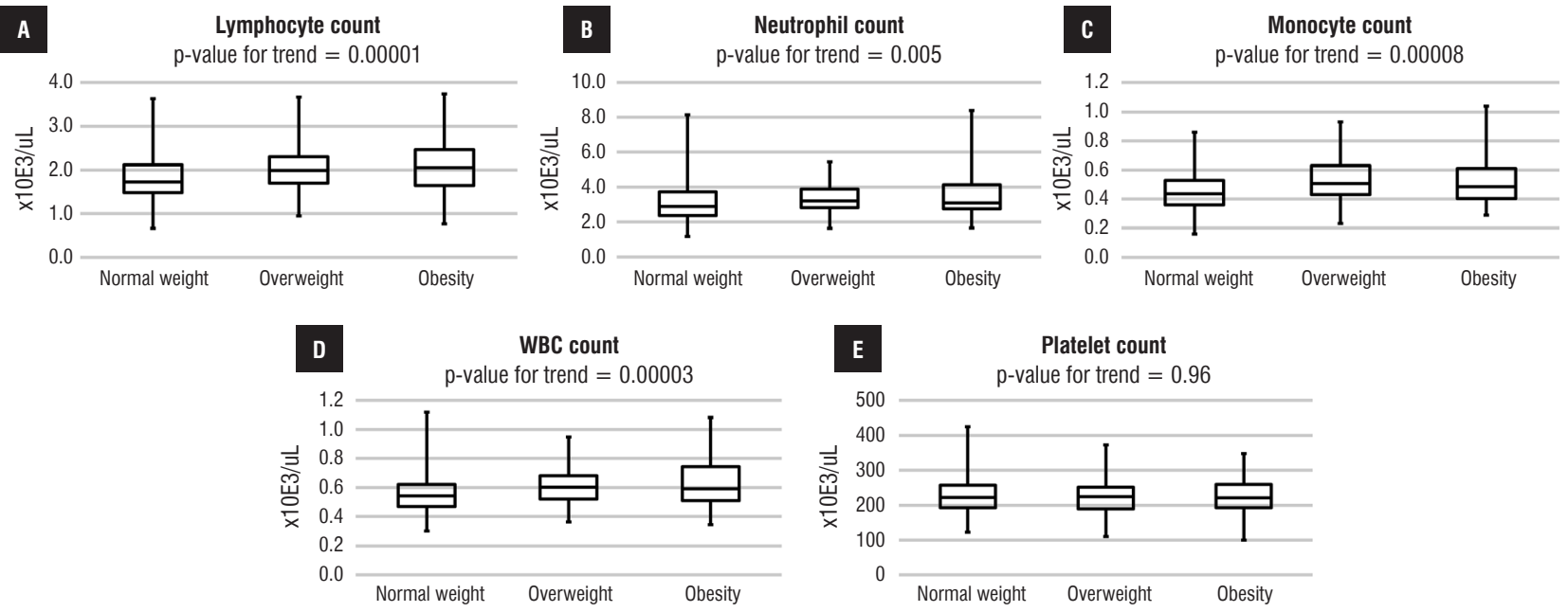

Figure 3. Comparison of lymphocyte $(\boldsymbol{A})$, neutrophil $(\boldsymbol{B})$, monocyte $(\boldsymbol{C})$, white blood cell $(\mathrm{WBC})(\boldsymbol{D})$, and platelet count $(\boldsymbol{E})$ between groups of normal weight, overweight, and obese subjects

Table V. Correlation coefficients between blood-based inflammatory biomarkers and established biomarkers of inflammation

\begin{tabular}{lcccccc}
\hline & \multicolumn{2}{l}{ Normal weight $(\mathbf{n}=\mathbf{1 5 8})$} & \multicolumn{2}{c}{ Overweight $(\mathbf{n}=\mathbf{1 1 2})$} & \multicolumn{2}{c}{ Obesity $(\mathbf{n}=\mathbf{5 1})$} \\
\hline & $\begin{array}{l}\text { Correlation } \\
\text { Coefficient }\end{array}$ & $\mathbf{p}$-value & $\begin{array}{l}\text { Correlation } \\
\text { Coefficient }\end{array}$ & p-value & $\begin{array}{c}\text { Correlation } \\
\text { Coefficient }\end{array}$ & $\mathbf{p}$-value \\
\hline NLR vs. hsCRP & 0.03 & 0.68 & 0.14 & 0.14 & 0.4 & 0.004 \\
\hline dNLR vs. hsCRP & 0.03 & 0.74 & 0.13 & 0.18 & 0.41 & 0.002 \\
\hline PLR vs. hsCRP & 0.1 & 0.2 & 0.25 & 0.007 & 0.25 & 0.08 \\
\hline LMR vs. hsCRP & -0.04 & 0.6 & 0.008 & 0.93 & -0.22 & 0.11 \\
\hline MHR vs. hsCRP & 0.07 & 0.37 & -0.02 & 0.87 & 0.23 & 0.1 \\
\hline NLR vs. fibrinogen & 0.18 & 0.02 & 0.12 & 0.2 & 0.5 & 0.0002 \\
\hline dNLR vs. fibrinogen & 0.19 & 0.02 & 0.09 & 0.34 & 0.55 & $<0.0001$ \\
\hline PLR vs. fibrinogen & 0.11 & 0.16 & 0.27 & 0.003 & 0.43 & 0.001 \\
\hline LMR vs. fibrinogen & 0.006 & 0.94 & -0.02 & 0.77 & -0.2 & 0.15 \\
\hline MHR vs. fibrinogen & -0.02 & 0.8 & 0.1 & 0.29 & 0.1 & 0.44 \\
\hline
\end{tabular}

NLR — neutrophil to lymphocyte ratio; hsCRP — high sensitivity C-reactive protein; dNLR — derived neutrophil to lymphocyte ratio; PLR — platelet to lymphocyte ratio; LMR — lymphocyte to monocyte ratio; MHR — monocyte to high-density lipoprotein ratio

\section{Funding source}

This study was supported by the research grant 2014/13/B/NZ5/03166 from the National Science Centre, Poland.

\section{References}

1. Rizzuto D, Fratiglioni L. Lifestyle factors related to mortality and survival: a mini-review. Gerontology. 2014; 60(4):327-335, doi: 10.1159/000356771, indexed in Pubmed: 24557026.

2. Arnlöv J, Sundström J, Ingelsson E. Impact of BMI and the Metabolic Syndrome on the Risk of Diabetes in Middle-Aged Men. Diabetes Care. 2011; 34(1): 61-65, doi: 10.2337/dc10-0955, indexed in Pubmed: 20852030.

3. Clarke PJ, O'Malley PM, Schulenberg JE, et al. Midlife health and socioeconomic consequences of persistent overweight across early adulthood: findings from a national survey of American adults (1986-2008). Am J Epidemiol. 2010; 172(5): 540-548, doi: 10.1093/aje/kwq156, indexed in Pubmed: 20610468.

4. Gokulakrishnan K, Ranjani H, Weber MB, et al. Effect of lifestyle improvement program on the biomarkers of adiposity, inflammation and gut hormones in overweight/obese Asian Indians with prediabetes. Acta
Diabetol. 2017; 54(9): 843-852, doi: 10.1007/s00592-017-1015-9, indexed in Pubmed: 28620678.

5. Klop B, Elte JW, Cabezas MC. Dyslipidemia in obesity: mechanisms and potential targets. Nutrients. 2013; 5(4): 1218-1240, doi:10.3390/nu5041218, indexed in Pubmed: 23584084.

6. Poddar M, Chetty Y, Chetty VT. How does obesity affect the endocrine system? A narrative review. Clin Obes. 2017; 7(3): 136-144, doi: 10.1111/cob.12184, indexed in Pubmed: 28294570.

7. Karelis AD. Metabolically healthy but obese individuals. Lancet. 2008; 372(9646): 1281-1283, doi: 10.1016/S0140-6736(08)61531-7, indexed in Pubmed: 18929889

8. Dyrbuś K, Osadnik T, Desperak P, et al. Evaluation of dyslipidaemia and the impact of hypolipidemic therapy on prognosis in high and very high risk patients through the Hyperlipidaemia Therapy in tERtiary Cardiological cEnTer (TERCET) Registry. Pharmacol Res. 2018; 132: 204-210, doi: 10.1016/j.phrs.2017.12.015, indexed in Pubmed: 29258913.

9. Phillips CM, Perry IJ. Does inflammation determine metabolic health status in obese and nonobese adults? J Clin Endocrinol Metab. 2013; 98(10): E1610-E1619, doi: 10.1210/jc.2013-2038, indexed in Pubmed: 23979951.

10. Song S, Li C, Li S, et al. Derived neutrophil to lymphocyte ratio and monocyte to lymphocyte ratio may be better biomarkers for predicting overall survival of patients with advanced gastric cancer. Onco Targets Ther. 2017; 10: 3145-3154, doi: 10.2147/OTT.S138039, indexed in Pubmed: 28706446. 
11. Wasilewski J, Desperak P, Hawranek M, et al. Prognostic implications of mean platelet volume on short- and long-term outcomes among patients with non-ST-segment elevation myocardial infarction treated with percutaneous coronary intervention: A single-center large observational study. Platelets. 2016; 27(5): 452-458, doi: 10.3109/09537104.2016.114391 9, indexed in Pubmed: 26939525.

12. Takeuchi H, Kawanaka H, Fukuyama S, et al. Comparison of the prognostic values of preoperative inflammation-based parameters in patients with breast cancer. PLoS One. 2017; 12(5): e0177137, doi: 10.1371/journal. pone.0177137, indexed in Pubmed: 28489884.

13. Nakamura T, Matsumine A, Matsubara T, et al. Infiltrative tumor growth patterns on magnetic resonance imaging associated with systemic inflammation and oncological outcome in patients with high-grade soft-tissue sarcoma. PLoS One. 2017; 12(7): e0181787, doi: 10.1371/journal. pone.0181787, indexed in Pubmed: 28727824.

14. Rajwa P, Życzkowski M, Paradysz A, et al. Novel hematological biomarkers predict survival in renal cell carcinoma patients treated with nephrectomy. Arch Med Sci. 2017: 1-10, doi: 10.5114/aoms.2017.70250.

15. Wasilewski J, Pyka Ł, Hawranek M, et al. Prognostic value of neutrophil-to-lymphocyte ratio in predicting long-term mortality in patients with ischemic and nonischemic heart failure. Pol Arch Med Wewn. 2016; 126(3): 166-173, doi: 10.20452/pamw.3316, indexed in Pubmed: 26991886.

16. Osadnik T, Wasilewski J, Lekston A, et al. The platelet-to-lymphocyte ratio as a predictor of all-cause mortality in patients with coronary artery disease undergoing elective percutaneous coronary intervention and stent implantation. J Saudi Heart Assoc. 2015; 27(3): 144-151, doi: 10.1016/j.jsha.2015.02.004, indexed in Pubmed: 26136628.

17. Rajwa P, Życzkowski M, Paradysz A, et al. Evaluation of the prognostic value of LMR, PLR, NLR, and dNLR in urothelial bladder cancer patients treated with radical cystectomy. Eur Rev Med Pharmacol Sci. 2018; 22(10): 3027-3037, doi: 10.26355/eurrev_201805_15060, indexed in Pubmed: 29863247.

18. Karataş MB, Çanga $\mathrm{Y}$, Özcan KS, et al. Monocyte to high-density lipoprotein ratio as a new prognostic marker in patients with STEMI undergoing primary percutaneous coronary intervention. Am J Emerg Med. 2016; 34(2): 240-244, doi: 10.1016/j.ajem.2015.10.049, indexed in Pubmed: 26585199.

19. Akboga MK, Balci KG, Maden O, et al. Usefulness of monocyte to HDL-cholesterol ratio to predict high SYNTAX score in patients with stable coronary artery disease. Biomark Med. 2016; 10(4): 375-383, doi: 10.2217/bmm-2015-0050, indexed in Pubmed: 26999570.

20. Osadnik T, Osadnik K, Pawlas N, et al. Metabolic and genetic profiling of young adults with and without family history of premature coronary heart disease (MAGNETIC). Study design and methodology. Arch Med Sc. 2018; [Epub ahead of print], doi: doi:10.5114/aoms.2018.75895.

21. Osadnik T, Pawlas N, Lonnie M, et al. Family history of premature coronary artery disease (P-CAD) - non-modifiable risk factor? Dietary patterns of young healthy offspring of P-CAD patients: a case-control study (MAGNETIC Project). Nutrients. 2018; 10(10): E1488, doi: 10.3390/nu10101488, indexed in Pubmed: 30322041.

22. Gromski PS, Muhamadali H, Ellis DI, et al. A tutorial review: Metabolomics and partial least squares-discriminant analysis--a marriage of convenience or a shotgun wedding. Anal Chim Acta. 2015; 879: 10-23, doi: 10.1016/j.aca.2015.02.012, indexed in Pubmed: 26002472.

23. Dahlén EM, Tengblad A, Länne T, et al. Abdominal obesity and low-grade systemic inflammation as markers of subclinical organ damage in type 2 diabetes. Diabetes Metab. 2014; 40(1): 76-81, doi: 10.1016/j.diabet.2013.10.006, indexed in Pubmed: 24290615.

24. Schmidt M, Saad M, Duncan B. Subclinical inflammation and obesity, diabetes and related disorders. Drug Discov Today: Dis Mech. 2005; 2(3): 307-312, doi: 10.1016/j.ddmec.2005.08.003.

25. Duncan BB, Schmidt MI. The epidemiology of low-grade chronic systemic inflammation and type 2 diabetes. Diabetes Technol Ther 2006; 8(1): 7-17, doi: 10.1089/dia.2006.8.7, indexed in Pubmed: 16472046.

26. de Heredia FP, Gómez-Martínez S, Marcos A. Obesity, inflammation and the immune system. Proc Nutr Soc. 2012; 71(2): 332-338, doi: 10.1017/S0029665112000092, indexed in Pubmed: 22429824.

27. Gregor MF, Hotamisligil GS. Inflammatory mechanisms in obesity. Annu Rev Immunol. 2011; 29: 415-445, doi: 10.1146/annurev-immunol-031210-101322, indexed in Pubmed: 21219177.

28. Rodríguez-Hernández H, Simental-Mendía LE, Rodríguez-Ramírez G, et al. Obesity and inflammation: epidemiology, risk factors, and markers of inflammation. Int J Endocrinol. 2013; 2013: 678159, doi: 10.1155/2013/678159, indexed in Pubmed: 23690772.

29. Ellulu MS, Patimah I, Khaza'ai H, et al. Obesity and inflammation: the linking mechanism and the complications. Arch Med Sci. 2017; 13(4): 851-863, doi: 10.5114/aoms.2016.58928, indexed in Pubmed: 28721154.

30. Cinkajzlová A, Mráz M, Haluzík M. Lymphocytes and macrophages in adipose tissue in obesity: markers or makers of subclinical inflammation? Protoplasma. 2017; 254(3): 1219-1232, doi: 10.1007/s00709-017-1082-3, indexed in Pubmed: 28150048.

31. Ghigliotti G, Barisione C, Garibaldi S, et al. Adipose tissue immune response: novel triggers and consequences for chronic inflammatory conditions. Inflammation. 2014; 37(4): 1337-1353, doi: 10.1007/s10753-014-9914-1, indexed in Pubmed: 24823865.

32. Vieira-Potter VJ. Inflammation and macrophage modulation in adipose tissues. Cell Microbiol. 2014; 16(10): 1484-1492, doi: 10.1111/cmi.12336, indexed in Pubmed: 25073615. 